\title{
Evidências cotidianas de resistência ao consumo como práticas individuais na busca pelo desenvolvimento sustentável
}

\author{
Everyday evidence of consumption resistance as individual practices in search of \\ sustainable development
}

Fernanda Kraemer ${ }^{1}$

Teniza da Silveira ${ }^{2}$

Carlos Alberto Vargas Rossi ${ }^{3}$

\begin{abstract}
Resumo
Este trabalho teve por objetivo conhecer as motivações para a resistência ao consumo que acompanham a questão do desenvolvimento sustentável; analisar as crenças e percepções sobre a resistência ao consumo, como forma de contribuir para o desenvolvimento sustentável e explorar a prática de resistência ao consumo no contexto de vida de consumidores nesse mesmo sentido. Para tanto, foram realizadas 21 entrevistas em profundidade com sujeitos que apresentam comportamentos de resistência ao consumo em geral, tentando compreender possíveis motivações, influências e práticas associadas a esse tipo de ato com foco na sustentabilidade. Os achados foram consistentes, em certos aspectos, com o que já foi encontrado na literatura - hábitos como produção caseira, redução da quantidade de produtos utilizados e substituição de alguns itens por outros foram práticas consideradas sustentáveis encontradas aqui. A alimentação parece ser o setor de consumo no qual a resistência ao consumo se manifesta mais fortemente; enquanto a rejeição a produtos com circuitos longos de produção - aparentemente inédita na literatura - emergiu como outro importante foco de atuação. Críticas ao governo brasileiro, por suas políticas de incentivo ao consumo, também foram encontradas, reforçando a ideia de que os cidadãos entendem que o caminho em direção a uma sociedade mais sustentável passa por ações individuais, mas, também, estatais.
\end{abstract}

Palavras-chave: Anticonsumo. Resistência ao consumo. Consumo sustentável.

\begin{abstract}
This paper aimed to understand the motivations for consumption resistance which follow the issue of sustainable development; to analyze the beliefs and perceptions on consumption resistance, as a contribution to sustainable development; and to explore the consumption resistance practice in the life context of consumers in the same way. For this, 21 in depth interviews were carried out with subjects presenting consumption resistance behaviors in general, trying to understand possible motivations, influences, and practices associated to this type of act with a focus on sustainability. The findings were consistent, in some aspects, with what has already been found in the literature - habits such as home production, decreased amount of products used, and replacement of some items by others were practices regarded as sustainable ones found here. Feeding seems to be the consumption sector where consumption resistance manifests
\end{abstract}

Artigo submetido em 30 de julho de 2012 e aceito para publicação em 16 de agosto de 2012.

${ }^{1}$ Mestre em Administração pela UFRGS. Endereço: Rua General Souza Doca, 172/201, Petrópolis, CEP 90630-050, Porto Alegre RS, Brasil. E-mail: fernandakra@gmail.com

2 Doutora em Administração pela USP; Professora Adjunta da UFRGS/EA. Endereço: Av. Juca Batista 8000, casa 1008, Belém Novo, CEP 91780-070, Porto Alegre - RS, Brasil. E-mail: teniza@terra.com.br

${ }^{3}$ Doutor em Administração pela USP; Professor Associado da UFRGS/PPGA. Endereço: Av. Juca Batista 8000, casa 1008, Bairro Belém Novo, CEP 91780-070, Porto Alegre - RS, Brasil. E-mail: cavrossi@ea.ufrgs.br 
itself most strongly; and the rejection to products with long production chains - something apparently unprecedented in the literature - emerged as another important focus of activity. Criticism to the Brazilian government, due to its policies to boost consumption, were also found, reinforcing the idea that citizens understand that the path towards a more sustainable society involves individual actions, as well as state actions.

Keywords: Anti-consumption. Consumer resistance. Sustainable consumption.

\section{Introdução}

A preocupação com os danos que o homem e seus hábitos de produção e consumo vêm causando à Terra não é recente. Essa temática já possui, há muitos anos, espaço garantido nas agendas política e midiática. Uma evidência disso foi a realização da conferência Eco 92 (que há vinte anos reuniu diversos chefes de Estado com o intuito de definir as políticas relativas a desenvolvimento sustentável nas décadas seguintes) e a recente conferência Rio +20 (organizada pela ONU em junho de 2012). Com o objetivo de discutir o compromisso político firmado por diferentes países e suas lacunas no que diz respeito à temática ambiental, o evento gerou repercussões entre neutras e negativas nos meios de comunicação, que consideraram muitas das resoluções ali trazidas insuficientes. Nesse sentido, pode-se dizer que o resultado prático desse tipo de evento pode não ser considerado por muitas pessoas suficiente para que a sociedade caminhe na direção de um planeta sustentável.

Assim, os cidadãos se veem na responsabilidade de agir nessa direção, que tem poucas oportunidades de atuação tão acessíveis como o consumo. Afinal, em uma sociedade onde todos são incentivados a consumir, pode residir aí uma situação na qual grande parte da população possa manifestar escolhas favoráveis ou contrárias a certos hábitos que podem contribuir para maior desgaste ou preservação do ambiente. Buscando se conectar a essa última questão, alguns indivíduos têm optado por mudanças significativas em suas práticas de consumo (DOBSCHA, 1998), chegando, muitas vezes, a diminuir drasticamente a quantidade de bens adquiridos. A esse fenômeno, a área de comportamento do consumidor denomina resistência ao consumo ou anticonsumo.

A partir da publicação do artigo de Peñaloza e Price (1993), "Consumer resistance: a conceptual overview", pode-se observar um nítido crescimento na referida área de estudos. Nove anos depois, no mesmo caminho, o representativo artigo de Kozinets (2002) sobre o festival Burning Man suscitou (e ainda suscita) discussões sobre o quanto é possível sairmos da lógica de mercado do sistema capitalista. De acordo com seus achados, especificamente, indica-se que é provável que as pessoas possam adotar hábitos de consumo diferentes daqueles adotados massivamente no mercado vigente apenas por pouco tempo e em território reduzido. Em contrapartida, outros artigos (DOBSCHA, 1998; ZAVESTOSKI, 2002b), já focados diretamente no campo de resistência ao consumo, sugerem que é possível, sim, que pessoas optem por viver consumindo menos, comprando menos e, até mesmo, descartando menos, ao longo de diversos anos e até mesmo em grandes cidades.

Essa busca por um estilo de vida não tão voltado para o consumo também tem sido cada vez mais um tema presente no cinema e na mídia. Filmes bastante conhecidos, como Trainspotting (1996) e Clube da Luta (1999), já vêm trazendo o questionamento ao consumo enquanto objetivo de vida. Em ambos os roteiros, o consumismo é questionado, evitado e negado pelos protagonistas por meio de práticas que envolvem drogas e violência - formas estas que certamente não são as únicas com as quais se pode consumir menos. Em paralelo, nos meios de comunicação, também se pode perceber cada vez mais matérias que mostram outras formas de viver que excluem o consumo excessivo de sua lógica. Apesar de grande parte das abordagens 
dadas ao tema falar de indivíduos que, sozinhos, buscam formas alternativas para viver ${ }^{4}$, também já é visível o aumento de grupos e entidades que lutam contra o consumo como objetivo de vida. Um exemplo é a organização New American Dream" ${ }^{5}$, que incentiva os indivíduos a buscar um "novo sonho americano". Para esse grupo de pessoas, a acumulação de bens não é sinônimo de sucesso, mas, sim, de miopia. A qualidade de vida, o tempo livre e a justiça social passam a ser, para os membros dessa organização, os maiores patrimônios que podem ser desejados. Essa visão já é compartilhada por milhares de pessoas ao redor do mundo, como os adeptos do movimento Simplicidade Voluntária entrevistados por Zavestoski (2002b), por exemplo.

Entretanto, a maior parte dos indivíduos ainda consome mais do que é exigido por suas necessidades básicas, utilizando os bens muitas vezes como forma de afirmar posições sociais. Na visão da New American Dream, por exemplo, pode-se dizer que as pessoas tendem a se focar mais naquilo que não importa (os bens e o dinheiro) do que naquilo que realmente importa (tempo livre para fazer aquilo de que se gosta). Mesmo podendo observar que já existem movimentações como essa no sentido de questionar o consumo como o principal objetivo de vida na sociedade contemporânea, ainda é necessário dizer que esse tipo de comportamento, que busca evitar o consumo em demasia e contribuir para a saúde do planeta, ainda representa um movimento de contracorrente.

Nesse sentido, gera curiosidade pensar quais aspectos podem fazer com que algumas pessoas passem a deixar o consumo em segundo plano, voltado para um papel mais utilitário e funcional, e optem por investir em outros aspectos de sua vida. Pensando em motivações que possam estar relacionadas à decisão de consumir menos, pode-se imaginar a influência de diferentes fatores, como culturais, religiosos, sociais e ambientais. Aqui, a preocupação com a sustentabilidade do planeta emerge cada vez mais frequentemente nos discursos relacionados ao consumo ou à sua redução. De acordo com uma ótica efetiva de sociedade sustentável, é imprescindível uma mudança de lógica sobre o que efetivamente é indispensável adquirir ou usar. Este último fenômeno está identificado com repensar social e culturalmente a lógica do consumo material (SCHUMACHER, 1974), que se reflete em uma mudança da estrutura normativa vigente, que iguala prosperidade material e riqueza, para outra baseada em uma estrutura anticonsumerista ética (PRESS e ARNOULD, 2009)

De acordo com Black e Cherrier (2010), a resistência ao consumo pode representar uma força motivadora inovadora para o desenvolvimento sustentável. Para esses autores, a maior parte dos estudos sobre sustentabilidade aponta que a maior probabilidade é de que práticas anticonsumo estão relacionadas a questões ambientais. O mesmo pode ser afirmado quanto ao consumo sustentável, quase sempre associado à sustentabilidade (HEISKANEN e PANTZAR, 1997).

Considerando a trajetória existente sobre pesquisas acerca de consumo sustentável ou resistência ao consumo, em que o desenvolvimento sustentável desponta como forte impulsionadora desses comportamentos, pretende-se avançar no entendimento da prática de resistência ao consumo no contexto brasileiro. Destaca-se que o reconhecimento dessas práticas em contextos restritos ainda não foi capaz de gerar um efeito propagador de vulto para a sociedade de forma mais ampla.

Objetiva-se com este trabalho: conhecer as motivações para a resistência ao consumo que acompanham a questão do desenvolvimento sustentável; analisar as crenças e percepções sobre a resistência ao consumo como forma de contribuir para o desenvolvimento sustentável e explorar a prática de resistência ao consumo no contexto de vida desses consumidores nesse mesmo sentido.

${ }^{4}$ Disponível em: <http://gooutside.uol.com.br/1487>. Acesso em: 3 maio 2012.

${ }^{5}$ Disponível em: <http://www.newdream.org/>. Acesso em: 3 maio 2012. 


\section{Referencial Teórico}

Nesta seção são discutidos os temas consumo sustentável, anticonsumo e resistência ao consumo. A ideia é trazer o contraponto do lado do consumidor para o debate do desenvolvimento sustentável. De forma geral, tem sido observada nesse tipo de discussão uma ênfase na exploração de como os consumidores compram produtos ecológicos. Mostramos abaixo que a literatura tem avançado no sentido de compreender esse contexto de forma mais ampla.

\section{Consumo sustentável}

Pleonexia, o termo grego empregado por Platão e Aristóteles, refere-se ao desejo natural e insaciável de ter mais. Quando refletimos sobre a participação dos cidadãos na agenda 21, esse conceito da filosofia nos faz pensar em como as pessoas podem responder de forma contrária a ele. Isto é, em uma situação de opulência, não só em nações ricas, mas, também, nas emergentes - como o Brasil, em que o acesso efetivo ao consumo passa a ser uma nova realidade para milhões de consumidores - como é possível consumir menos e melhor? Essa é a grande discussão subjacente ao conceito de consumo sustentável, que é definido de forma um pouco vaga na literatura. A sustentabilidade é definida pela ONU, em 1987, como o atendimento das necessidades do presente sem comprometer a capacidade das gerações futuras satisfazerem suas próprias necessidades (HUANG e RUST, 2011).

Huang e Rust (2011) exploram como consumidores, empresas e governos inter-relacionam-se com respeito à sustentabilidade e consumo. As consequências ambientais devem ser analisadas tanto do ponto de vista do nível macro como do micro. No micro, há um consumidor representativo e uma empresa representativa que interagem no mercado. No macro, os autores apontam a presença de todos os consumidores, as corporações, o agregado das firmas (societal) e o agregado de todos os mercados em todas as áreas geográficas que constituem a economia. Sendo assim, não há desenvolvimento sustentável sem que compreendamos a lógica de todos os lados da sociedade. O foco de análise deste trabalho recai sobre o nível micro e, mais especificamente, sobre os consumidores.

Gilg, Barr e Ford (2005), a partir do estudo de 1.600 lares em Devon, na Inglaterra, sugerem que o consumo verde deve ser encarado como consumo sustentável ou um componente de qualquer mudança na direção de um estilo de vida sustentável que evoca não apenas atos relacionados à compra, mas, também, comportamentos de uma forma mais holística no cotidiano das pessoas.

Jackson (2005) aponta que, a despeito dos esforços empreendidos pela indústria ecológica a partir dos anos 1990 no sentido de aumento da eficiência de produção, nada garante que os consumidores irão comprar os produtos mais verdes ou a que a escala de produção material não permanecerá dentro dos limites ecológicos. O mais relevante para o consumo sustentável é a lógica do duplo dividendo, na qual se deve desenvolver a habilidade de viver melhor consumindo menos e de reduzir nosso impacto sobre o meio ambiente ao longo do processo (JACKSON, 2005). Como Feldman (1971 apud HUANG e RUST, 2011, p. 44) apontou, há mais de 40 anos, os consumidores reconheciam de forma crescente que o aumento de consumo material individual podia não ser compatível com o bem-estar da sociedade como um todo e poderia gerar consequências adversas ao meio ambiente. Tais evidências nos levam a pensar em outro aspecto da discussão acerca do consumo sustentável, que diz respeito à passagem da consciência ou discurso à prática. Nessa linha, compreender a dinâmica dos movimentos de anticonsumo e resistência ao consumo pode ser útil para o avanço da disseminação do consumo sustentável. 


\section{Anticonsumo e resistência ao consumo}

Como já dito, o primeiro artigo a trabalhar com o fenômeno de resistência ao consumo é de autoria de Peñaloza e Price (1993) (ROUX, 2007; LEE et al., 2011). Nesse trabalho, as autoras trouxeram o conceito como relacionado a atos nos quais os consumidores buscam resistir ao consumo enquanto uma estrutura de dominação. Desde essa publicação, o campo de estudos relacionados à resistência a consumo tem crescido constantemente - apesar de poucas definições sobre o que esse conceito é, de fato, terem sido escritas (ROUX, 2007). Assim, o foco nesse tema refere-se a questões sobre as relações de poder existentes entre os consumidores e outros atores que comporiam uma força dominante de mercado (LEE et al., 2011).

Em paralelo ao campo de resistência ao consumo, faz-se necessário pontuar um conceito fortemente relacionado a esse, o de anticonsumo. Tendo como base os achados do trabalho de Galvagno (2011), reiterados por Lee et al. (2011), podemos considerar que, enquanto o conceito de resistência ao consumo se referiria a ações que buscam resistir ao "consumir" enquanto estrutura de dominação, os comportamentos de anticonsumo não teriam necessariamente por objetivo lutar contra o consumo enquanto força dominante, e estariam sempre diretamente relacionados ao processo de consumo. $\mathrm{O}$ anticonsumo - que literalmente significa contra o consumo (LEE, FERNANDEZ e HYMAN, 2009) - nessa visão, seria sempre dependente do consumo - como no caso de indivíduos que optam por boicotar uma marca mas passam a comprar produtos de outra fabricante. Assim, a preocupação aqui recairia sobre como o consumo é afetado nesse tipo de ato, enquanto nos estudos de resistência ao consumo a principal questão está posta sobre as relações de poder existentes entre o consumidor e o mercado. Pode-se destacar que a resistência ao consumo poderia ocorrer por meio de gestos de anticonsumo, mas isso não faria com que todo ato de resistência ao consumo seja um ato de anticonsumo, nem com que todo ato de anticonsumo seja um ato de resistência ao consumo.

Contudo, aqui vale ressaltar que as tentativas de estabelecer uma divisão entre as definições de resistência ao consumo e anticonsumo são bastante recentes (LEE et al., 2011; GALVAGNO, 2011) e trazem indicações de diferenças entre os dois temas que, até então, não haviam vindo à tona. Analisando a forma com a qual os dois conceitos são concebidos nesses trabalhos, fica bastante evidente certa dificuldade em delimitar resistência ao consumo e anticonsumo, e como a interação entre os dois construtos acontece. Lee et al. (2001), inclusive, dizem que, na prática, a maior parte dos trabalhos escritos sobre resistência ao consumo e anticonsumo tratam os dois temas de maneira sobreposta. Em paralelo, existiriam pouquíssimos artigos tratando unicamente sobre resistência ao consumo, mas nenhum somente sobre anticonsumo. Fazendo uso do raciocínio de Lee et al. (2011), acredita-se que não é possível utilizar essa tentativa de segmentação entre anticonsumo e resistência ao consumo para analisar separadamente trabalhos relacionados a esses temas. Assim, deste ponto em diante, neste trabalho o estudo das pesquisa realizadas sobre a área não será feito dividindo os achados entre aqueles denominados como "anticonsumo" ou "resistência a consumo", mas, sim, de acordo com a proximidade de tratamento e fenômenos estudados.

Se fôssemos realizar um esforço no sentido de posicionar este trabalho de acordo com as definições de anticonsumo e resistência ao consumo de Galvagno (2011) e Lee et al. (2011), diríamos que essa pesquisa se aproximaria mais do campo de estudos de anticonsumo, pois tratamos, aqui, sobre motivos individuais que podem influenciar as formas com as quais uma pessoa consome.

No sentido de nomenclatura, Kozinets, Handelman e Lee (2010) advogaram que o termo anticonsumo é derivado de uma visão negativa a respeito do consumo, focada em ganância, individualismo e hedonismo. Para os autores, se o foco das pesquisas passasse a estar no potencial humano, generosidade e sentido de comunidade que podem estar envolvidos no consumo, não deveríamos estar falando em um anticonsumo, mas, sim, em fenômenos pró-humanidade, em uma era pós-consumo. Assim, dada a fragilidade teórica da divisão das áreas de anticonsumo e resistência ao consumo, e em consonância com esses autores, este trabalho não irá priorizar a nomenclatura anticonsumo, mas, sim, resistência ao consumo, quando fala de comportamentos relacionados à preferência por não consumir de maneira mais abrangente. 
Buscando compreender como o tratamento dado a anticonsumo e resistência ao consumo evolui com o passar dos tempos, Galvagno (2011) sinalizou que, cada vez mais, as pesquisas acerca dessa temática estão saindo da discussão sobre resistência ao poder e indo em direção a questões relacionadas a identidade própria e autodefinição.

Essa tentativa de situar os estudos relacionados à resistência ao consumo em diferentes categorias precede o trabalho de Galvagno (2011). Diversos autores (PEÑALOZA e PRICE, 1993; FOURNIER, 1998; STAMMERJOHAN e WEBSTER, 2002; CLOSE e ZINKHAN, 2009; IYER e MUNCY, 2009; KOZINETS, HANDELMAN e LEE, 2010; SUAREZ, CHAUVEL e CASOTTI, 2012) também fizeram tentativas de organizar ou categorizar diferentes tipos de comportamentos de resistência ao consumo. Ao tentar compreender os aspectos principais desse tipo de ato, as motivações, objetivos e objetos envolvidos foram aspectos especialmente ressaltados. Nesse sentido, comportamentos que possuem como fundamento causas pessoais, por exemplo, geralmente diferem categoricamente daqueles que são baseados em motivações coletivas, pertencendo, assim, a tipos distintos.

\section{Tipologias de anticonsumo ou resistência ao consumo}

Além de ser as primeiras pesquisadoras a tratar do tema resistência ao consumo, Peñaloza e Price (1993) também foram as primeiras a tentar criar uma organização de diferentes tipos de comportamento do gênero. As autoras organizaram os fenômenos de resistência do consumidor em um esquema de quatro dimensões, que seriam: 1) dimensão organizacional do ato de resistência, que pode ser uma ação individual ou coletiva; 2) objetivos relacionados, que podem ser reformistas ou radicais; 3 ) táticas adotadas pelos consumidores, que podem ir desde uma alteração do sentido do consumo até ações diretas, buscando modificações no marketing mix de uma empresa; e 4) importância da relação do consumidor com instituições e agentes de marketing, que pode utilizar uma empresa como ferramenta para seus atos de resistência ou atuar distante dela, independentemente ou priorizando outros tipos de organizações. Um aspecto interessante dessa categorização é que ela inclui até mesmo atos de ressignificação de uso e dos próprios produtos, como, por exemplo, quando um consumidor passa a utilizar sua geladeira como porta-recados, ou quando passa a considerar um bem não só pelo seu valor utilitário, mas pelas emoções envolvidas no momento da compra um exemplo de comportamento que fica excluído das outras categorizações encontradas.

Fournier (1998) também procurou esquematizar esses fenômenos, criando um "continuum de resistência", no qual os comportamentos adotados pelos consumidores foram distribuídos em três diferentes espécies: comportamentos de evasão em um extremo, comportamentos de minimização no centro e rebelião ativa em outro extremo. Os comportamentos de evasão são aqueles nos quais o consumidor opta por evitar um produto ou marca específicos. Os comportamentos de minimização incluem estratégias de enfrentamento (como regular o andamento do processo de concepção de produtos) e atitudes do tipo downsizing (quando os consumidores optam por reduzir a quantidade de bens consumidos de maneira geral). Já os do tipo rebelião ativa, contemplam reclamações, boicotes e atitudes de consumidores que decidem sair do universo de consumo, opondo-se ao mercado. Assim, podemos inferir que a autora teve o grau de resistência manifestado pelos indivíduos como critério principal para a concepção de tal esquema - indo desde o simples ato de evitar uma marca até o que seria uma tentativa de sair da lógica de consumo vigente.

Essa tipologia, em particular, foi bastante criticada por Roux (2007), cujas principais observações residem no fato de que, ao compreender os fenômenos de resistência ao consumo como dispostos em um continuum, Fournier (1998) entende que todos os atos ali alocados diferem apenas em intensidade, mas não em causa ou natureza. Assim, a discussão teórica giraria apenas em torno dos comportamentos de resistência ao consumo, e não daquilo que os desencadeia.

Trabalhando com a nomenclatura "não consumo" e focando-se em atos de fundo mais prático do que político, Stammerjohan e Webster (2002) definiram quatro categorias de comportamentos do gênero: atraso, 
economia, autocontrole e ignorância. Os que se encaixam na categoria de atraso podem acontecer devido a uma grande ansiedade no momento da compra ou a um desejo de manter outras opções em aberto, fazendo com que o consumidor opte por não tomar decisão alguma, não efetuando a aquisição. Já a categoria economia contempla não compras que tiveram como razão uma vontade do indivíduo de economizar dinheiro, seja comprando outro produto com menor preço, seja simplesmente não comprando produto algum. Autocontrole, a terceira categoria, contempla motivações sociais e individuais do consumidor, além de poder ser tanto um meio (autocontrole para que se possa passar determinada imagem para outros) quanto um fim (o autocontrole pelo seu simples exercício, com fundo religioso, por exemplo). Finalmente, há os comportamentos de não compra do tipo ignorância, fundamentados por uma falta de desejo de consumir. Essa falta de desejo pelo consumo pode ter como causa uma sensação de saciedade, que varia de acordo com cada pessoa. Assim, o que pode ser insuficiente para um indivíduo, que deseja continuar consumindo, pode ser suficiente para outro, que se dá por satisfeito.

No campo de resistência ao consumo, Close e Zinkhan (2009) realizaram uma pesquisa sobre comportamentos de indivíduos que evitavam consumir no Dia dos Namorados. Tomando esse fenômeno como base, os autores buscaram avançar na teoria segmentando diferentes tipos de resistência: 1) resistência a presentes; 2) resistência ao varejo; e 3) resistência ao mercado. O primeiro ocorreria quando os consumidores estipulam limites para as trocas de presentes - que podem ser relacionados a preço, estabelecendo um teto máximo para o custo, ou até mesmo não dando nenhum item. Já a resistência ao varejo estaria ligada ao ato de evitar lojas específicas, que sejam associadas a determinados eventos ou datas. Por último, os autores introduzem o conceito de resistência ao mercado, no qual podemos contemplar aqueles que não comemoram a data de nenhuma maneira, não aderindo a comportamentos culturalmente relacionados a essa celebração.

Iyer e Muncy (2009), por sua vez, propuseram uma categorização diferente dos tipos de anticonsumo, divididos em quatro categorias: 1) geral-societal (que contempla indivíduos que reduzem seu consumo com o intuito de diminuir o impacto causado no ambiente, por exemplo); 2) geral-pessoal (representado, inclusive, por simplificadores voluntários, na visão dos autores); 3) marca-societal (tipo de comportamento adotado por ativistas de mercado, como os do Greenpeace); e 4) marca-pessoal (que inclui até consumidores que não são leais a marcas). Por último, é importante notar que as categorias derivadas da matriz desenvolvida por Iyer e Muncy (2009) não são mutuamente excludentes, logo, um indivíduo pode estar reduzindo seu consumo por mais de uma das (ou até mesmo por todas as) razões apontadas. Aqui, é importante ressaltar que essa classificação proposta por Iyer e Muncy (2009) obtém suporte empírico segundo a meta-análise sobre anticonsumo e resistência ao consumo realizada por Galvagno (2011). De acordo com o autor, essa tipologia corresponde às formas com as quais a maioria das pesquisas de resistência ao consumo tem compreendido e estudado o campo dos fenômenos do gênero.

Muito similares à classificação apresentada por Iyer e Muncy (2009) são os tipos de anticonsumo definidos por Kozinets, Handelman e Lee (2010). Aqui, os critérios para compreensão dos atos de resistência dos consumidores são muito semelhantes aos dos primeiros autores: especificidade situacional (específica ou geral) e quadro motivacional (pessoal ou moral/coletivo). De acordo com esse esquema, os indivíduos "anticonsumistas" poderiam ser de quatro tipos: ativista (específico-coletivo), utópico (geral-coletivo), expressivo (pessoal-específico) e transformativo (pessoal-geral).

No Brasil, um recente estudo realizado por Suarez, Chauvel e Casotti (2012) explorou o comportamento de abandono de categoria (carros e cigarro) e trouxe a possibilidade de os comportamentos de anticonsumo ser adotados com o objetivo de trazer diferenciação afirmativa, positiva e de reforço da autoestima. Ali, foram identificados três tipos de abandono: o contigencial, o posicional e o ideológico. $\mathrm{O}$ abandono contingencial seria aquele que ocorre quando, mesmo compartilhando significados com outros consumidores da categoria, o sujeito se vê obrigado a deixar de consumir determinado produto. $\mathrm{O}$ abandono do tipo posicional seria causado, em maior parte, por uma negação às associações simbólicas relativas àquele item. Já o abandono 
ideológico, por último, traria consigo uma ótica coletiva, na qual o indivíduo entende que a sociedade como um todo deveria reduzir ou abandonar o consumo daquele bem.

\section{Quadro 1}

Diferentes tipologias de resistência ao consumo/anticonsumo/não consumo

\begin{tabular}{|c|c|c|}
\hline Autores & Nomenclatura utilizada & Tipos \\
\hline Peñaloza e Price (1993) & Resistência do consumidor & Não se aplica. \\
\hline Fournier (1998) & Resistência do consumidor & $\begin{array}{l}\text { Comportamentos de evasão, } \\
\text { comportamentos de minimização, } \\
\text { rebelião ativa. }\end{array}$ \\
\hline Stammerjohan e Webster (2002) & Não consumo & $\begin{array}{c}\text { Atraso, economia, autocontrole e } \\
\text { ignorância. }\end{array}$ \\
\hline Close e Zinkhan (2009) & Resistência do consumidor & $\begin{array}{l}\text { Resistência a presentes, resistência } \\
\text { ao varejo, resistência ao mercado. }\end{array}$ \\
\hline Iyer e Muncy (2009) & Anticonsumo & $\begin{array}{l}\text { Geral-societal, geral-pessoal, marca- } \\
\text { societal, marca-pessoal. }\end{array}$ \\
\hline $\begin{array}{l}\text { Kozinets, Handelman e Lee } \\
\qquad(2010)\end{array}$ & Anticonsumo & $\begin{array}{l}\text { Ativista (específico-coletivo), utópico } \\
\text { (geral-coletivo), expressivo (pessoal- } \\
\text { específico) e transformativo (pessoal- } \\
\text { geral). }\end{array}$ \\
\hline Suarez, Chauvel e Casotti (2012) & Anticonsumo & Contingencial, posicional, ideológico. \\
\hline
\end{tabular}

Fonte: Elaborado pelos autores.

A maioria das pesquisas sobre resistência ao consumo possui orientação qualitativa, e analisam um único contexto onde comportamentos desse tipo se desenvolvem por vez (ROUX, 2007). Além disso, como já sinalizado por Galvagno (2011) em sua meta-análise, um dos comportamentos mais estudados pelo campo de resistência ao consumo é o de indivíduos praticantes da simplicidade voluntária. Esse movimento, que tem sido analisado por diversos autores (ETZIONI, 1998; CRAIG-LEES e HILL, 2002; ZAVESTOSKI, 2002b; SHAW e NEWHOLM, 2002), é composto por pessoas que, por vontade espontânea, optam por limitar seus gastos com bens e serviços, buscando cultivar fontes de satisfação não materiais (ETZIONI, 1998).

Comportamentos de indivíduos que optaram por reduzir a quantidade de bens consumidos, mas sem se declarar adeptos da simplicidade voluntária, também foram estudados. Dobscha (1998), inclusive, pesquisou especificamente como mulheres atuam no intuito de reduzir seu contato com o mercado. A resistência a ações de natureza publicitária também é um tema tratado pela área de resistência ao consumo (RUMBO, 2002). Boicotes relacionados a marcas específicas também são um tema recorrente no estudo de resistência ao consumo. As causas para esse tipo de postura por parte dos consumidores pode variar: mudança de localização de uma fábrica (HOFFMAN e MÜLLER, 2009), práticas empresariais que são condenadas pelos consumidores, como a caça a focas (BRAUNSBERGER e BUCKLER, 2011), relação da marca com datas 
comemorativas que os consumidores rejeitam (CLOSE e ZINKHAN, 2009), ou até mesmo questões ideológicas contrárias ao país de origem da empresa (VARMAN e BELK, 2009). Além de comportamentos do tipo downsizing e boicotes, outras situações nas quais a resistência ao consumo se manifestou também foram pesquisadas, como o Dia dos Namorados (CLOSE e ZINKHAN, 2009).

Entretanto, a resistência ao consumo também pode ocorrer pelo contato e uso de bens. O trabalho de Varman e Belk (2009), por sua vez, traz a relação entre anticonsumo voltado à marca Coca-Cola, na Índia, e a ideologia nacional swadeshi. Foi entendido que, ali, o "não consumo", era justamente o locus de atuação daqueles que resistiam à dominação ocidental. Havia uma ideologia por trás das ações de boicote realizadas, e os atos de anticonsumo eram necessários para reforçar a materialidade da ideologia swadeshi. Nesse sentido, a marca Coca-Cola representava os inimigos dos indianos, enquanto a resistência apresentada ao consumo de seus produtos materializava a resistência à dominação americana. Cherrier (2010), por sua vez, identificou que pessoas com o hábito de guardar muitos objetos, especialmente artesanais, também manifestam resistência ao consumo, pois creem que esses bens possuem mais validade do que novas aquisições, fabricadas por máquinas, e não manualmente. Assim, aparece a indicação de que atos de resistência ao consumo não estão necessariamente ligados à negação de bens materiais, pois estes podem estar intrinsecamente relacionados à adoção desse tipo de comportamento (VARMAN e BELK, 2009; CHERRIER, 2010). Esse entendimento vai ao encontro da afirmação de Peñaloza e Price (1993) de que, muitas vezes, atos dessa natureza não buscam mudar a lógica de consumo vigente ou sair dela, pois várias dessas atitudes podem estar presentes no cotidiano dos indivíduos, em processos de uso e significação dos bens.

Percebe-se que a motivação envolvida nos comportamentos do consumidor é uma questão crucial para que seus atos sejam ou não definidos como de resistência ao consumo. Como foi sinalizado por Galvagno (2011), essas motivações (sociais ou pessoais) dos indivíduos para a adoção de comportamentos de resistência ao consumo têm sido um aspecto cada vez enfatizado pelas pesquisas - especialmente por teóricos que trabalham com uma abordagem relacionada à pós-modernidade (CHERRIER, 2007; 2009). Nesse sentido, além da importância de compreender quais objetivos um consumidor resistente tem, sobrevém uma necessidade de entender como aspectos pessoais podem influenciar atos de resistência ao consumo.

\section{Causas e antecedentes de anticonsumo ou resistência ao consumo}

Diferentes causas podem ser apontadas para a adoção de comportamentos de resistência ao consumo. Essas motivações variam, principalmente, de acordo com a natureza dos atos em questão. Podem ser motivadas por lucro, questões políticas, morais ou relacionadas à sustentabilidade ambiental (CRAIG-LEES, 2006). Por outro lado, a resistência ao consumo também pode ser um fruto de um estilo de vida com mais tempo livre, mas menos recursos financeiros (ZAVESTOSKI, 2002b) - como no caso de muitos participantes do movimento simplicidade voluntária.

Em seu estudo com mulheres que se rebelaram contra o mercado, Dobscha (1998) trouxe a resistência ao consumo como resposta a um mercado que não reflete os valores e preocupações dessas pessoas. Assim, por achar o mercado ineficiente, materialista e com tendência para o desperdício, optaram por tentar se afastar dele. Para Cherrier (2009), um ponto em comum entre indivíduos que adotam atitudes contra o consumo é a expressão de um desejo de combater ou afetar a chamada cultura de consumo. Além disso, de acordo com Rumbo (2002), a opção pela saída do mercado pode ser uma alternativa escolhida pelos indivíduos para evitar o desconforto de uma dissonância cognitiva entre a imagem do que são e a imagem do que a mídia lhes diz que é perfeito.

Outro fator que pode ser relacionado à opção pelo não consumo é o religioso. Para a maioria das religiões, a aquisição em excesso é desencorajada, o que pode influenciar alguns indivíduos (LASTOVICKA et al., 1999). Na cultura contemporânea, a literatura de autoajuda recomenda uma vida mais simples como forma 
de atingir objetivos a longo prazo, dando dicas para adotar esse modelo. Alguns comportamentos de resistência ao consumo apresentados pelas entrevistadas de Dobscha (1998), inclusive, são sugeridos como táticas para a adoção de um estilo de vida mais sóbrio. Assim, o mesmo ato de não consumo pode ter diferentes motivações (ecológicas, ideológicas ou de economia) (LASTOVICKA et al., 1999). Nesse sentido, a compreensão que o pesquisador tem sobre o conceito de resistência ao consumo pode fazer com que o mesmo gesto possa ser interpretado como pertencente a essa categoria ou não.

A frugalidade também teve seus antecedentes estudados. Por trás dos comportamentos que gera, esse estilo de vida (LASTOVICKA et al., 1999)tem como principal razão a necessidade de reduzir desperdício, sendo uma demonstração de como os indivíduos consideram suas compras e a experiência de compra. Assim, consumidores frugais não estão em busca de objetivos como crescimento pessoal, por exemplo, como no caso dos adeptos da simplicidade voluntária (BOVE, NAGPAL e DORSETT, 2009).

Para Zavestoski (2002a; 2002b), comportamentos de resistência ao consumo são adotados mais provavelmente por indivíduos que tenham dificuldade para atingir algumas necessidades fundamentais por meio do consumo. Dentre as três bases motivacionais do self enumeradas pelo autor (estima, eficácia e autenticidade), somente as duas primeiras poderiam ser obtidas através do consumo. Assim, se entendemos o consumidor com base na hierarquia adaptada de Maslow utilizada pelo autor, é possível concluir que o consumo não é um meio que pode, sozinho, levar os indivíduos à felicidade e à realização pessoal completa. Dessa forma, um sentimento de insatisfação com a vida também pode ser considerado um antecedente de comportamentos de resistência ao consumo.

\section{Método}

Tendo em vista a perspectiva de que a análise da sustentabilidade do ponto de vista do consumo ainda necessita ser aprofundada, que os mecanismos subjacentes à adoção do comportamento individual em prol da sustentabilidade ainda precisam ser mais conhecidos e, por outro lado, seu conhecimento é fundamental para se obter um efeito multiplicação, optou-se pela condução de um estudo de natureza exploratória. Foram entrevistadas 21 pessoas em uma capital brasileira que apresentavam comportamentos de resistência ao consumo. As análises tiveram como foco indivíduos que possuíam tendência a evitar o consumo de uma maneira geral, tanto por motivações pessoais como morais/coletivas - seguindo a tipologia de resistência ao consumo desenvolvida por Kozinets, Handelman e Lee (2010), são os chamados tipos transformativos (motivações pessoais) e utópicos (motivação coletiva). A escolha por tal perfil se deu pelo entendimento de que comportamentos dessas categorias, que buscam evitar o consumo de uma forma mais abrangente, representam o fenômeno de resistência ao consumo de maneira mais intensa, no que seria representado pelo extremo do contínuo desenvolvido por Fournier (1998), citado anteriormente. Segundo esse esquema, os comportamentos de resistência ao consumo podem ser de três diferentes tipos, variando de menor para maior intensidade (comportamentos de evasão, comportamentos de minimização e rebelião ativa, respectivamente).

A busca por respondentes seguiu o critério de bola de neve. Foram contatadas associações que têm como um de seus pilares a resistência ao consumo como o do Sítio da Amizade e a Comuna do Arvoredo (ou "Casaredo") - comunidade urbana formada por quatro casas situadas no Centro Histórico de Porto Alegre e que são habitadas por pessoas que possuem em comum forte inspiração ecológica.

O roteiro semiestruturado criado para as entrevistas era composto de doze perguntas, que contemplavam práticas de consumo e resistência ao consumo, além das motivações dos entrevistados para a manifestação desses comportamentos. As entrevistas em profundidade foram realizadas pessoalmente entre os meses de fevereiro e março de 2012, em ambientes distintos, escolhidos pelos respondentes. Em algumas situações (três, mais especificamente), os indivíduos foram entrevistados via Skype - como no caso de uma participante residente no Mato Grosso do Sul e de outra pessoa residente no Japão. Nas entrevistas presenciais (18 das 21 realizadas), os principais locais de encontro foram as residências dos entrevistados, 
que em dois casos eram comunidades (Casaredo e Sítio da Amizade) onde residiam com outras pessoas também resistentes ao consumo. Esses casos, em especial, possibilitaram uma maior compreensão do meio no qual os entrevistados vivem, fazendo com que posse possível observar in loco algumas das práticas de resistência ao consumo relatadas nas entrevistas - no Sítio da Amizade, por exemplo, foi possível constatar práticas de reaproveitamento de lenha e água, bem como de consumo reduzido de alimentos (preferencialmente orgânicos ou colhidos no próprio sítio).

O material obtido totalizou cerca de 13 horas de gravação, transcritas pessoalmente pelos pesquisadores em 91 páginas. Baseando-se nos dados recebidos nos encontros foi realizada uma análise de conteúdo (BARDIN, 1977), que gerou diferentes categorias e subcategorias - aprofundadas abaixo. A divisão das categorias foi realizada com o auxílio de dois analistas independentes. Posteriormente, a análise prosseguiu sendo feita somente pelos pesquisadores.

\section{Resultados e Análise}

Como explicitado anteriormente, os entrevistados foram localizados por meio de indicações feitas para os pesquisadores e contato com membros de grupos com perfil de resistência ao consumo - vale ressaltar que alguns respondentes foram indicados por outros participantes. Dessa forma, chegou-se a 21 indivíduos (Quadro 2), que foram entrevistados tendo como base um questionário semiestruturado.

\section{Quadro 2}

\section{Perfil dos entrevistados}

\begin{tabular}{|c|c|c|c|}
\hline Entrevistado(a) & Descrição & Entrevistado(a) & Descrição \\
\hline $\begin{array}{l}\text { Entrevistada A, } \\
\text { Feminino, } 49\end{array}$ & $\begin{array}{l}\text { Auditora fiscal. } \\
\text { Artista plástica. }\end{array}$ & $\begin{array}{l}\text { Entrevistada L, } \\
\text { Feminino, } 26\end{array}$ & $\begin{array}{l}\text { Administradora. Estudante } \\
\text { (Doutorado - Administração). }\end{array}$ \\
\hline $\begin{array}{l}\text { Entrevistado B, } \\
\text { Masculino, } 51\end{array}$ & $\begin{array}{l}\text { Artista de teatro. Ator. } \\
\text { Diretor. Produtor. }\end{array}$ & $\begin{array}{l}\text { Entrevistado M, } \\
\text { Masculino, } 32\end{array}$ & $\begin{array}{l}\text { Engenheiro Agrônomo. } \\
\text { Estudante (Doutorado - } \\
\text { Administração). }\end{array}$ \\
\hline $\begin{array}{l}\text { Entrevistada C, } \\
\text { Feminino, } 54\end{array}$ & Auditora fiscal. & $\begin{array}{c}\text { Entrevistada N, } \\
\text { Feminino, } 32\end{array}$ & Professora (inglês e espanhol). \\
\hline $\begin{array}{l}\text { Entrevistada D, } \\
\text { Feminino, } 25\end{array}$ & $\begin{array}{l}\text { Cozinheira. Estudante } \\
\text { (Graduação - Letras). }\end{array}$ & $\begin{array}{l}\text { Entrevistado O, } \\
\text { Masculino, } 29\end{array}$ & Desempregado. \\
\hline $\begin{array}{l}\text { Entrevistado E, } \\
\text { Masculino, } 28\end{array}$ & $\begin{array}{l}\text { Professor. Tutor de ensino } \\
\text { a distância. }\end{array}$ & $\begin{array}{l}\text { Entrevistada } P, \\
\text { Feminino, } 29\end{array}$ & $\begin{array}{c}\text { Estudante (Graduação - } \\
\text { Biologia). }\end{array}$ \\
\hline $\begin{array}{l}\text { Entrevistada F, } \\
\text { Feminino, } 27\end{array}$ & Bartender. & $\begin{array}{l}\text { Entrevistado Q, } \\
\text { Masculino, } 30\end{array}$ & $\begin{array}{l}\text { Permacultor. Educador } \\
\text { ambiental. Estudante. }\end{array}$ \\
\hline
\end{tabular}


Continuação do Quadro 2

\begin{tabular}{|c|c|c|c|}
\hline Entrevistado(a) & Descrição & Entrevistado(a) & Descrição \\
\hline $\begin{array}{l}\text { Entrevistada G, } \\
\text { Feminino, } 32\end{array}$ & Jornalista. Repórter. & $\begin{array}{l}\text { Entrevistada R, } \\
\text { Feminino, } 26\end{array}$ & Educadora. \\
\hline $\begin{array}{l}\text { Entrevistada } \mathrm{H} \text {, } \\
\text { Feminino, } 33\end{array}$ & $\begin{array}{c}\text { Jornalista. Repórter voluntária. } \\
\text { Estudante (Mestrado - } \\
\text { Jornalismo). }\end{array}$ & $\begin{array}{l}\text { Entrevistado S, } \\
\text { Masculino, } 33\end{array}$ & Artista. Músico. Palhaço. \\
\hline $\begin{array}{l}\text { Entrevistado I, } \\
\text { Masculino, } 29\end{array}$ & $\begin{array}{c}\text { Estudante (Mestrado - } \\
\text { Psicologia). }\end{array}$ & $\begin{array}{l}\text { Entrevistada T, } \\
\text { Feminino, } 61\end{array}$ & $\begin{array}{c}\text { Professora (Graduação e pós- } \\
\text { graduação, Comunicação - } \\
\text { Jornalismo). }\end{array}$ \\
\hline $\begin{array}{l}\text { Entrevistado J, } \\
\text { Masculino, } 24\end{array}$ & $\begin{array}{c}\text { Cozinheiro. Artista. Tradutor. } \\
\text { Músico. Auxiliar } \\
\text { administrativo. Estudante } \\
\text { (Graduação - História). }\end{array}$ & $\begin{array}{l}\text { Entrevistado U, } \\
\text { Masculino, } 30\end{array}$ & Professor (Biologia). \\
\hline $\begin{array}{c}\text { Entrevistada K, } \\
\text { Feminino, } 28\end{array}$ & Designer. Cervejeira. & & \\
\hline
\end{tabular}

Fonte: Elaborado pelos autores.

Como explicitado anteriormente, as entrevistas foram gravadas, transcritas e submetidas a uma análise de conteúdo (BARDIN, 1977), por meio da qual foi possível chegar a categorias referentes aos comportamentos de resistência ao consumo desenvolvidos pelos respondentes (vide Quadro 3). Dentro de cada um desses itens, por sua vez, foram identificadas diferentes subcategorias, demonstrando como, um por um, tais aspectos se manifestava para os entrevistados.

Quadro 3

Categorias e subcategorias emergentes da análise de conteúdo

\begin{tabular}{|c|c|}
\hline Categorias & Subcategorias \\
\hline Por que resistir? & Desenvolvimento sustentável \\
\cline { 2 - 2 } $\begin{array}{c}\text { Motivações e influências para a adoção de } \\
\text { comportamentos de resistência ao } \\
\text { consumo }\end{array}$ & Educação familiar \\
\cline { 2 - 2 } & Contato com outras pessoas e culturas \\
\cline { 2 - 2 } Onde resistir? & Bem-estar \\
\hline \multirow{2}{*}{\begin{tabular}{c} 
Objetos da resistência ao consumo \\
\cline { 2 - 2 }
\end{tabular}} & Alimentação \\
\cline { 2 - 2 } & Marcas específicas \\
\cline { 2 - 2 } & Vestuário \\
\hline
\end{tabular}


Continuação do Quadro 3

\begin{tabular}{|c|c|}
\hline \multirow{2}{*}{ Categorias } & Subcategorias \\
\hline \multirow{2}{*}{$\begin{array}{c}\text { Como resistir? } \\
\text { Práticas de consumo }\end{array}$} & Produtos com circuitos longos de produção e consumo \\
\cline { 2 - 2 } & Reutilização e reaproveitamento \\
\cline { 2 - 2 } & Produção caseira \\
\cline { 2 - 2 } & Condições: Importância das redes, do preço e do tempo \\
\hline \multirow{2}{*}{ Percepções sobre consumo } & Críticas ao consumo em excesso (consumismo) \\
\cline { 2 - 2 } & Críticas à publicidade e ao marketing verde \\
\hline \multirow{2}{*}{ Fazer $\times$ ter } & Valorivas de consumo \\
\hline & Valorização de experiências: fazer $>$ comprar \\
\hline
\end{tabular}

Fonte: Elaborado pelos autores.

\section{Por que resistir?}

A primeira categoria, motivações e influências para a adoção de comportamentos de resistência ao consumo, é composta por quatro subcategorias que indicam quais são as principais causas que foram apresentadas no discurso dos indivíduos para a adoção de comportamentos de resistência ao consumo. Desenvolvimento sustentável, educação familiar, contato com outras pessoas e culturas, e bem-estar foram os principais fatores influenciadores apontados pelos indivíduos para resistir ao consumo. Na primeira subcategoria em questão, desenvolvimento sustentável, encontra-se aquela que foi a motivação apresentada mais frequentemente pelos entrevistados. A questão ambiental é um importante fator influenciador para a adoção de comportamentos de resistência ao consumo. O consumo em excesso e suas consequências geração de lixo, escassez de riquezas naturais, poluição - são citados como cruciais na opção por consumir menos, de uma forma "mais consciente", nas palavras dos entrevistados. O ponto principal, aí, está no entendimento de que o atual modelo de consumo é insustentável e indubitavelmente leva ao esgotamento do planeta. A preocupação com o excesso de consumo no mundo e a repercussão que tais gastos geram é constantemente relatada. A opção por consumir menos ocorre tendo como uma das principais motivações a redução dos impactos ambientais gerados pelo atual excesso de produção e descarte de bens.

Já na segunda subcategoria, educação familiar, o papel da família foi apontado como fundamental na decisão dos entrevistados em adotar de comportamentos de resistência ao consumo. Aqui, a instrução para consumir menos e de maneira planejada vem, primeiramente, dos familiares dos sujeitos. Tais relatos trazem - em sua maioria - a lembrança de uma infância humilde e simples, onde os entrevistados não tiveram a oportunidade de gastar quase nada além do estritamente necessário. Em um cenário no qual, muitas vezes, imperava a escassez de recursos materiais, a orientação familiar prezava pela redução de gastos e pelo consumo somente do que era considerado essencial. Na terceira subcategoria se situa outra grande influência que se apresenta na adoção de comportamentos de resistência ao consumo, o contato com outras pessoas e culturas que já trabalham com costumes e hábitos diferentes daqueles desenvolvidos pela maioria da população. Assim, o início de uma concepção de redução de consumo pode vir da aproximação com grupos, pessoas e culturas que já ajam dessa forma. Nesse sentido, o questionamento dos valores vigentes na sociedade pode surgir por 
meio do contato com outras culturas, como no caso da entrevistada R, por exemplo, que após conviver com uma tribo indígena na Amazônia passou a repensar e modificar seus hábitos de consumo. Já na última subcategoria de motivações para resistência ao consumo, bem-estar, foram referidas convicções que acompanham os indivíduos desde quando têm lembrança. A preferência por consumir menos, nesses casos, é considerada natural pelos respondentes, estando, muitas vezes, associada a bem-estar. Tal achado é compatível com o que apontam Black e Cherrier (2010). Um caso no qual essa percepção se manifesta nitidamente é o do Entrevistado E que, naturalmente, desenvolveu um interesse por esse modo de vida, considerado por ele mais compatível com o que acredita.

Acho que [evitar o consumismo] é uma questão de visão de mundo, o que é que me faz feliz. Acho que é simplesmente isso. Eu preciso disso? Por que eu preciso disso aí? Roupas, o negócio da ostentação, ou até luxos... é uma opção de ir numa coisa ética, ideológica. [...] Eu já pensei várias coisas, porque eu tô no ambientalismo há sete anos. Eu acho que uma coisa é coerência do que eu acredito. Eu não comer mamíferos (eu como peixe), então, eu acredito nisso e sigo isso aí, nas minhas limitações. Tem gente que até é muito mais radical. [...] Eu mudei meus hábitos de consumo porque eu me sinto bem assim, fazendo isso (Entrevistado E).

Vendo dessa forma, mudar os hábitos de consumo também passa a ser uma ferramenta para reduzir a dissonância cognitiva entre aquilo que o indivíduo acha que é certo e aquilo que ele faz. Nesse sentido, consumir menos é uma forma de estar em paz com aquilo que se acredita ser o melhor para si, para a sustentabilidade do planeta e para o restante da sociedade.

Em casos do Entrevistado E, a preferência por consumir pouco, com o passar dos anos, geralmente é respaldada em leituras realizadas pelos sujeitos, que passam a encontrar ali embasamento para convicções que já carregavam desde antes. Assim, é importante frisar que o contato com literatura e teorias que defendem uma redução do consumo não foram, nesses casos, o ponto de partida para a adoção dos comportamentos em questão, apenas serviram para ajudar a desenvolver uma justificativa para um sentimento que já era latente nos indivíduos.

\section{Onde resistir?}

Já a segunda categoria, objetos da resistência ao consumo, é composta por quatro subcategorias que contemplam os tipos de evasão mais comuns no grupo entrevistado: alimentação, marcas específicas, vestuário e produtos com circuitos longos de produção e consumo. A alimentação é o setor de consumo onde a resistência a determinados produtos e marcas se manifesta mais fortemente. Nesse sentido, as motivações são relacionadas a cuidados com a saúde, preservação ambiental e lógicas de produção das quais os entrevistados discordam. Quase todos os entrevistados contatados são vegetarianos, ou pelo menos não comem mamíferos ou carne vermelha, por motivações que podem ser as relacionadas acima. O ponto destacado mais fortemente é a relação entre a criação de gado e a sustentabilidade do planeta. Apesar dos dados quantitativos em relação aos litros de água e quilos de alimento consumidos pelo gado variar de acordo com o discurso de cada respondente, a grande quantidade de recursos e esforços despendidos em prol da produção da carne vermelha são alvos de críticas constantes. Carne de frango, enlatados, embutidos, refrigerantes e margarina são outros dos produtos evitados, principalmente pelo potencial de danos que eles podem trazer à saúde, segundo os entrevistados. $\mathrm{O}$ acondicionamento dos alimentos, muitas vezes, e não o alimento em si, também é capaz de gerar rejeição nos consumidores. Afinal, quanto mais embalagens são utilizadas, mais lixo é gerado - mais prejuízo ao desenvolvimento sustentável - e mais riscos elas podem oferecer à saúde. Além de evitar categorias de produtos completas, marcas específicas também costumam ser rejeitadas. Empresas de diferentes segmentos - alimentício, petrolífero, bancário e vestuário - são recusadas pelos indivíduos. No grupo, a Coca-Cola e o McDonald's foram apontadas como as marcas mais rejeitadas. 
A qualidade dos produtos (considerados artificiais e nocivos à saúde) e as práticas de tratamento aos seus funcionários foram as principais causas para essa evasão. A Bunge, joint venture que fabrica fertilizantes e óleos de cozinha, é evitada por seu conhecido trabalho com soja transgênica. A Elma Chips, por também ser suspeita de trabalhar com alimentos transgênicos, entra igualmente na lista de marcas que esses consumidores evitam trazer para casa. A Texaco e a Shell, por acidentes relacionados a derramamento de petróleo, também são evitadas. A propaganda, que já havia sido trazida por Dobscha (1998) como uma prática que gera revolta nos resistentes ao consumo, aparece, aqui, da mesma forma. A Nike e a Coca-Cola, especialmente, são evitadas e muito criticadas por seu forte investimento em publicidade. O vestuário, área na qual a moda e sua lógica de descarte do antigo pelo novo se torna mais evidente (LIPOVETSKY, 1989), é justamente uma das categorias nas quais a rejeição ao consumo parece atuar de forma mais forte. As roupas são vistas como supérfluas, e esses consumidores tentam utilizá-las simplesmente por sua função utilitária. A troca de peças antigas por novas se dá em ciclos espaçados ao máximo. Na lógica aqui utilizada, os itens podem ser utilizados até esgotar sua capacidade de uso, ficando excessivamente velhas - sem nenhum compromisso com a moda e tendências de consumo, assim como constatado por Dobscha (1998). Da mesma forma, roupas "de marca", ou seja, de fabricantes que praticam altos preços ou possuem marcas consagradas, são dispensadas e até mesmo rejeitadas. Por último, produtos com circuitos longos de produção e consumo também foram apontados como foco da rejeição dos entrevistados. Em diversos segmentos, os indivíduos preferem não consumir produtos que sejam produzidos em locais muito distantes daquele onde estão comprando. A proposta desse tipo de recusa é evitar contribuir com sistemas nos quais há um número muito grande de intermediários e o consumidor se encontra cada vez mais distante do produtor. A opção por comprar produtos produzidos em locais mais distantes do consumidor acarretaria um consumo maior de energia e petróleo, causado pelo transporte realizado entre o polo de produção e o local de compra - algo que pode ser considerado ruim, em termos ambientais. Em paralelo, quando o número de intermediários entre o produtor e o consumidor é muito grande, entende-se que, para o produto chegar às prateleiras com um preço aceitável, muitos daqueles que cooperaram com esse processo estariam sendo explorados, vendendo seu trabalho por um preço muito baixo a fim de possibilitar essa quantia pedida no ponto de venda. Essa ideia é trazida de forma bastante clara na fala do Entrevistado U:

No mercado também, ter preferência por produtos que são produzidos próximo, se eu tenho
como escolher um produto que é produzido aqui no RS ou em SP, então, eu escolho, por
causa do consumo de energia, em relação ao transportes. E, às vezes, a gente não se dá nem
conta, ainda mais com as facilidades que tem quase todos os produtos que tu vai ver são
fabricados na China, made in China. Nas lojas de R $\$ 1,99$, os produtos vêm de outros
países e tudo, e no final não é só em relação ao trabalho, porque tu deixas de gerar trabalho
aqui, mas, também em relação principalmente ao consumo de energia. Porque, mais ou
menos, podemos pegar um exemplo de quando um produto é produzido na Ásia, ás vezes,
só o transporte consome 40 vezes mais petróleo do que produzido internamente
(Entrevistado U).

Assim, pode-se entender que comprar produtos que foram fabricados ou produzidos em locais mais distantes é considerada uma prática nociva social e ambientalmente. Essa concepção, como se verá adiante, está fortemente relacionada à preferência dos entrevistados por consumir produtos fabricados por pessoas conhecidas.

\section{Como resistir?}

Práticas de consumo, a terceira categoria, circunda alguns dos hábitos adotados por aqueles que buscam reduzir seu consumo de uma maneira geral. Assim, foram identificados quatro tipos de situações, todas convergentes com os pressupostos do desenvolvimento sustentável: 1) reutilização e aproveitamento; 2) produção caseira; 3) busca por formas alternativas de consumo; 4) condições: importância das redes, do 
preço e do tempo. Na primeira subcategoria, reutilização e aproveitamento, estão reunidos atos nos quais os consumidores reaproveitam bens que já possuem em casa ou que foram doados, com o intuito de evitar a aquisição de novos itens. Nesse sentido, muitos dos achados se assemelham aos da pesquisa de Dobscha (1998) com mulheres resistentes ao consumo, que buscavam adaptar e reutilizar objetos que já possuíam. Entretanto, o processo de reutilização observado não ocorre somente com itens que pertenciam aos sujeitos, mas, também, com itens que foram arrecadados, como presente de pessoas que iriam descartá-los. A realização de ajustes em roupas antigas, por exemplo, é uma prática bastante recorrente entre as mulheres, e que, muitas vezes, é realizada pelas próprias entrevistadas. No item produção caseira, pode-se constatar a preferência por produzir certos produtos em casa, em vez de comprá-los. Entrevistados disseram optar por fabricar diversos itens em ambiente doméstico sempre que possível. Cadernos, objetos de decoração, barras de cereal, pão, cigarros, produtos de limpeza, pó dental e bicicletas são alguns dos itens produzidos pelos próprios consumidores. No caso dos primeiros itens, cadernos e objetos de decoração, pode-se observar um papel quase terapêutico desempenhado pelo ato de produzir, ressignificando produtos que iriam para o lixo e transformando-os em itens únicos e personalizados. Em função de razões supracitadas, como a preferência por evitar produtos industrializados ou com circuitos longos de consumo, a busca por formas alternativas de consumo se faz necessária entre aqueles que adotam comportamentos de resistência ao consumo. Enquanto shoppings são evitados - à exceção de alguma emergência ou uma eventual ida ao cinema -, lugares alternativos são valorizados. Nesse sentido, pontos de venda como mercados de bairro, feiras locais e voltadas para agricultura familiar, o Mercado Público de Porto Alegre e a banca do Movimento dos SemTerra (MST), especificamente, são procurados pelos entrevistados para a realização de compras periódicas. A saudabilidade dos alimentos e a valorização do trabalho do produtor rural também são algumas das motivações relacionadas à escolha desse tipo de estabelecimento. Na quarta subcategoria, condições: importância das redes, do preço e do tempo, estão inseridas práticas relacionadas a estruturas que facilitem a adoção de comportamentos de resistência de consumo. Como já trazido por Kozinets (2002), a possibilidade de criar diferentes formas de consumir depende fortemente de laços criados entre diferentes pessoas com propósitos similares ou, pelo menos, relacionados. Assim, encontrar viabilidade nesses caminhos de consumo passa pela criação e/ou entrada em redes de relacionamento relativas àquilo que se busca substituir, compartilhar ou consumir de outro modo. Os relatos abaixo ilustram bem esse ponto:

Tem aqui uma coisa muito de bairro, e o engraçado é que, aqui, tem um mercadinho na esquina que a gente já começou a fazer um lance meio de escambo. Eu fiquei amiga da dona do mercadinho, da filha dela, e elas sabem que eu cozinho, e elas também cozinham. Então, às vezes a gente pega um monte de tomate na feira, daí faz os molhos nos potes e congela. Daí, eu vou lá e dou um pote de molho pra ela e digo: "ah, eu tô precisando de uns ovos”, e ela: "ah, pega ali”, aí a gente já começou a fazer umas coisas assim. A minha conclusão é meio que, com certeza no bairro isso é outra realidade. Nunca que eu morando na Cidade Baixa eu ia conseguir fazer isso com a minha vizinha, porque eu nem sabia quem era a minha vizinha. Mas, aqui, rola mais (Entrevistada D).

Buscar consumir coisas que não se troca por dinheiro só, mas outras formas de consumo, relações de consumo. Por exemplo, a vizinha aqui, ela tem uma vaca, a gente não tem vaca. Então, a gente faz geleia, dá pra ela, aí ela dá uma manteiga, então... é outra forma de consumir, né? Consumir a manteiga, mas aqui da vizinha. Acho que o espaço rural, aqui, possibilita mais tu perceberes isso. Tipo, por isso que a gente optou por viver aqui [no Sítio da Amizade] (Entrevistada R).

Em ambos os casos, seja no escambo combinado pela Entrevistada D com os donos do mercadinho de seu bairro, seja nas trocas realizadas pela Entrevistada R com a vizinha do Sítio da Amizade, esses processos só se tornam possíveis porque os participantes contam com outras pessoas que também estão dispostas a substituir sistemas de compra e venda tradicionais por outros mais alternativos. Indo além, a importância de grupos que, mais do que consumam sustentavelmente, também discutam seus hábitos de consumo de forma 
reflexiva já foi apontada por Portilho (2005), que traz a força dos grupos e das redes como um possível primeiro passo em direção a atos que contemplem a esfera pública.

Contudo, além do grupo, vale ressaltar que, grande parte das formas supracitadas como práticas de redução de consumo - produção própria, reutilização e aproveitamento e busca de formas alternativas de consumo exige tempo dos membros da comunidade para ser concretizadas. Tempo para aprender a fazer, para fazer e para finalmente poder desfrutar aquilo que foi criado. E é o tempo, justamente, uma das maiores reivindicações daqueles que desejam reduzir ou alterar ainda mais sua forma de consumir.

\section{Percepções sobre o consumo}

A quarta categoria, percepções sobre consumo, traz duas frentes do discurso dos consumidores acerca da realidade atual relacionada ao tema. Na primeira, críticas ao consumo em excesso (consumismo), encontra-se a crença compartilhada pelo grupo de que a sociedade, de uma maneira geral, consome mais do que o necessário - e que esse consumo é alimentado pelo Estado. O consumismo é trazido como um ponto essencial para a manutenção do sistema capitalista, o que, por sua vez, faz com que todos percam. Afinal, não existiriam recursos suficientes para a manutenção de um padrão de consumo excessivo por parte de todos os cidadãos, uma vez que tal formato seria ambientalmente insustentável. O governo brasileiro, assim, é muito criticado por trabalhar com uma compreensão de desenvolvimento que toma o consumo como sinônimo de progresso.

O [governo do] Brasil acha que - inclusive é uma crítica em relação à essa ideologia de progresso que está posta - de achar que todo mundo vai poder ter acesso a esse tipo de consumo, e não é verdadeiro, porque não há recursos minerais, agrícolas, naturais suficientes pra esse tipo consumo. [...] Há quase que um consumo imposto na sociedade (Entrevistado U).

A relação com o consumo é uma relação de conflito, e eu acho que é estressante também, porque eu acho que tem muita pressão pra gente consumir. E eu acho revoltante que o governo fique pressionando a gente pra consumir. E é a economia do consumo, como incentivar o crescimento, como incentivar o consumo... sendo que o governo sabe que isso é um paliativo pra economia do país, porque a gente fica tendo picos de crescimento, mas não vai resolver o nosso problema da distribuição de renda, ou de emprego, ou de geração de emprego (Entrevistada H).

Dessa forma, a lógica estabelecida na sociedade, onde todos devem competir para ter cada vez mais, chocase diretamente com as concepções e valores dos respondentes, que prezam pela manutenção das relações sociais, buscando coexistência, e não competitividade. A importância da coletividade é um ponto reforçado por aqueles que buscam uma forma alternativa de consumir. Nesse sentido, a fala dos entrevistados E e $\mathrm{S}$ (que vivem em comunidades de verve ecológica - Comunidade do Arvoredo e Sítio da Amizade) são bastante representativas:

O consumo é o grande propulsor do capitalismo. Que é, na verdade, uma lógica suicida. Então, o consumo, na verdade, é a forma de destruir o planeta, e destruir também as pessoas, as relações sociais. Isso é precificação de tudo, de todo esse discurso. Essa confusão entre o valor e o preço. Acho que esse seria o grande vilão dessa sociedade (Entrevistado E).

O consumismo foi pro ego. A gente vai muito mais longe quando tá todo mundo junto. E agora não tá todo mundo junto, tem muita fome, muita matança, muita guerra pra alimentar 
cada vez mais uma energia que... esse consumismo é a forma de normatizar as pessoas, só tecnologia e estudo voltado pra isso, deixar as pessoas zumbis (Entrevistado $\mathrm{S}$ ).

Em críticas à publicidade e ao marketing verde, os consumidores trazem uma atitude negativa em relação à publicidade em geral. Os participantes consideram as campanhas publicitárias como representantes de um sistema que incentiva as pessoas a consumir, independente de haver necessidade real ou não. A ideia de que a publicidade converte desejos em necessidades, por exemplo, é bastante forte entre os entrevistados. Essa percepção mostra-se com ênfase ainda maior quando o tema é a divulgação de produtos do segmento de tecnologia, como celulares, computadores, tablets etc. Assim como a publicidade, a apropriação da questão "verde" é igualmente considerada inadequada e, por isso, rejeitada pelos respondentes. Para eles, as marcas utilizam um tema sério - como a importância de ações sustentáveis e ecologicamente viáveis - para vender mais, distorcendo, assim, o debate que originou essa concepção. Um exemplo seria a questão relativa às sacolas de plástico, que vêm sendo banidas dos supermercados no país. O foco inicial, que seria a redução da quantidade de plástico gerado e descartado em cada ida às compras, acabou sendo direcionado mais a uma questão de estilo do que ecológica. Consequentemente, o papel socioambiental que deveria ser desempenhado pelos indivíduos é subvertido em função da falta de informação (a qual é pouco disponibilizada pelas empresas e, ao mesmo tempo, pouco requerida pelos consumidores).

Tem a sacola de pano, aí o cara vai lá e compra a sacola de pano do Zaffari porque, ah, puxa, legal, sou verde. Mas a sacola de pano do Zaffari vem da China. E aí? Isso, pra mim, é muito importante e, ao mesmo tempo, é muito gostoso, quando dá pra pensar nas implicações, na complexidade mesmo (Entrevistado I).

Uma das coisas centrais no nosso sistema é esse apelo consumista, é fazer com que o alternativo se torne uma opção também, que pode ser vendida ou comprada. Tem um grupo de que eu participo do movimento ambientalista, a gente até analisa às vezes as propagandas de TV, assim, que tudo é vendido. Tinha várias, eu me lembro agora da tinha, eu acho que a Palio Weekend, que no final, a rebeldia e o contato com a natureza dependiam do carro, lá, um $4 \times 4$, etc. e tal, e é isso. Tudo, a Eco Sport, tu vai ver, tudo é incorporado (Entrevistado U).

O ponto trazido aqui vai ao encontro das ideias de Naomi Klein (2002) sobre a indústria do cool - o processo no qual o mercado está sempre em busca de novos temas para se apropriar e converter em produtos. Criticando o conceito de cool e os chamados coolhunters, a autora afirma que esse tipo de pesquisa, na verdade, seria uma tentativa das marcas de entender e controlar fenômenos de rebeldia jovem. Os indivíduos identificados com esse tipo de perfil, segundo a autora, seriam a última grande reserva de consumidores que restou para as grandes corporações, o que justifica a exploração desse nicho. Nesse sentido, o cool ainda seria um fenômeno um tanto quanto impalpável, e o trabalho do coolhunter seria exatamente o de apropriarse dos últimos espaços ainda livres de marcas - como é o caso das culturas marginais, dos estilos de rua, das atitudes psicológicas (como a própria indiferença e a ironia, características do público jovem) e, mais recentemente, do passado. Para Klein (2002), os coolhunters reduzem ideias culturais vibrantes a meros artefatos arqueológicos, exaurindo os significados que possuem originalmente.

E essa ideia, por sua vez, é a mesma que se tem do chamado marketing ecológico ou marketing verde. Para os entrevistados, a divulgação de produtos tidos como ecológicos soa como uma situação na qual as empresas tiram proveito da questão ambiental, sem, de fato, fazer algo que realmente beneficie o planeta (DOBSCHA, 1998). 


\section{Fazer $\times$ ter}

$\mathrm{Na}$ última categoria, fazer $\times$ ter, são destacados dois pontos sobre a relação entre os consumidores e aquilo que podem fazer e/ou ter. O "ter", nesse contexto, aparece como um conceito relacionado ao "fazer", podendo ser precedido por ele (quando os indivíduos estão criando os próprios objetos) ou substituído por ele (quando as pessoas optam por viver experiências em vez de adquirir novos bens materiais). Na primeira subcategoria, valorização de experiências, pode-se entender que o gosto por experiências de diversos tipos é um ponto fortemente trazido pelos entrevistados. O interesse por leitura, estudo, manifestações culturais e convívio social aparece como um ponto importante da vida e do dia a dia. A opção por passar o tempo desenvolvendo atividades ligadas a esse tipo de experiências é trazida, inclusive, como relacionada ao consumo material, em um sistema de compensação:

Eu consumo outras coisas, aí não fico muito preocupado com consumir, porque igual eu tô vivendo, eu aproveito a vida, em vez de aproveitar pra consumir. [...] Aí, eu tento consumir as coisas que vão fazer eu me sentir bem. Como estar jogando meus malabares e estar fazendo uma poesia. Eu acho que, dessa forma, eu vou fazer alguma coisa, com a minha arte (Entrevistado $\mathrm{S})$.

A relação entre experiências e bens materiais, assim, surge em uma lógica de substituição, onde se opta por viver algo em vez de consumir novos itens. De certa forma, observa-se que o tempo que se passa realizando outras atividades passa a ocupar o tempo em que se poderia estar comprando ou desenvolvendo outras atividades consideradas menos "nobres". A fala do Entrevistado I mostra como o consumo de experiências, para ele, é considerado um "consumir com consciência", estando em uma categoria distinta daquela na qual estão os demais gastos.

E é um tanto complexo pra mim, acho que é isso, eu não gosto quando eu noto uma exposição ao consumo, que às vezes é algo que vem de fora de mim, mas às vezes é algo bem interno mesmo. Agora eu gosto de consumir, mas querendo consumir com consciência. Gosto de escolher a cerveja que eu vou beber... ou ver um filme hollywoodiano, que não me traz nada além de algumas horas de diversão. Eu gosto de filmes... ou, então, consumir um filme europeu, ou aquele filme B, sabe? Isso também é consumo (Entrevistado I).

Em outro caso, mesmo evitando consumir em diversos aspectos (como vestuário, tecnologia, eletrodomésticos etc.), o Entrevistado $\mathrm{M}$ diz valorizar bebidas de qualidade, como bons vinhos e boas cervejas. Informa, ainda, que ir ao cinema e jantar fora de casa também são programas valorizados. Pode-se entender, assim, que o consumo de bens culturais ou de experiências pagas não é considerado desperdício.

Já na última subcategoria, valorização de experiências: fazer > comprar, entende-se que, assim como experiências culturais podem ser valorizadas enquanto lazer e fontes de bem-estar, pode-se estender essa compreensão a outro tipo de experiência: a de produzir seus próprios objetos de consumo. Nos estudos sobre comportamento do consumidor, a experiência é definida como um episódio subjetivo na construção e transformação do indivíduo, possuindo uma ênfase sobre as emoções e sentidos vividos durante a imersão, em detrimento da dimensão cognitiva (CARU e COVA, 2003). Com base nisso, se analisarmos as falas trazidas pelos consumidores anteriormente (categoria produção caseira), fica evidenciada não só a importância funcional de produzir algo que substituirá um bem que poderia ser comprado, mas também o processo prazeroso, de aprendizado e autoconhecimento que está incluso nesse ato.

Tem várias coisas [que gosto de fazer em casa] pão, por exemplo, eu adoro fazer pão. [...] Essas coisas de higiene eu acho que eu gostaria de fazer, desodorante também, são produtos 
que não é pra isso, eu ponho em um recipiente que é pra isso e uso... Teve essa época que eu fazia xampu, eu era bem feliz, em experimentar (Entrevistado I).

Assim, quando produzem para seu próprio consumo, os consumidores vivenciam o que Xie, Bagozzi e Troye (2008, p. 110) denominam prosumption, que "é um processo, mais do que um simples ato (como a compra) e consiste em uma integração de atividades físicas, esforço mental e experiências sociopsicológicas". Ao fazer, e não comprar, há um investimento de tempo, esforço e habilidades por parte do prosumer (XIE, BAGOZZI e TROYE, 2008), que desenvolve também uma relação de proximidade e extensão com os objetos criados (ROSSI et al., 2006). A experiência de criar para consumo próprio, assim, não é um momento único, composto de início, meio e fim, mas sim, um processo que ultrapassa o período dedicado à criação e produção.

\section{Considerações Finais e Sugestões para Pesquisas Futuras}

No que diz respeito às práticas e motivações para resistir ao consumo apresentadas pelos entrevistados, além de ter sido possível comprovar alguns achados de outros pesquisadores, chegou-se a constatações que acrescentam elementos à lista daqueles estudados na área de resistência ao consumo.

Muitas causas já apontadas por Zavestoski (2002b) e Craig-Lees e Hill (2002) - como busca de uma vida mais autêntica e com maior bem-estar, priorizando questões existenciais, e não econômicas - também reverberam neste estudo. Entretanto, alguns pontos aparecem, aqui, como diferencial: a influência familiar e de outras pessoas ainda é um ponto que não foi tratado na literatura - de acordo com a pesquisa bibliográfica realizada. No sentido aqui disposto, a motivação se dá em muito pelo meio social, e não somente por vontades intrínsecas dos sujeitos - a exemplo das pesquisas de Zavestoski (2002b) e Dobscha (1998), por exemplo.

Muitas das práticas e percepções identificadas (como produção caseira, reaproveitamento de itens que iriam para o lixo, compra de produtos de segunda mão, negação do uso de vestuário "da moda" e críticas à publicidade) estão em consonância com os achados de Dobscha (1998). O compartilhamento de bens, trazido por Ozanne e Ballantine (2010) como uma prática de resistência ao consumo, também aparece neste trabalho. Entretanto, aqui, mais do que compartilhar itens, os entrevistados partilham espaços físicos, como no caso do Sítio da Amizade (cujo terreno abriga as casas de três membros e uma cozinha de uso comum) e da Comunidade do Arvoredo. Os achados de Craig-Lees e Hill (2002), segundo os quais os resistentes ao consumo preferem consumir bens de marcas não conhecidas ou de segunda mão (como já foi dito), também foram validados neste trabalho. Esta pesquisa também está alinhada à indicação de Gould, Houston e Mundt (1997) de que muitos indivíduos boicotam empresas por estar insatisfeitos com suas práticas de negócios. Nesse sentido, o uso de propaganda, os maus-tratos aos funcionários e a exploração do ambiente surgem como atos condenáveis em ambos os estudos. Particularmente, a negação de produtos com circuitos longos de produção e consumo parece ser uma nova prática a ser identificada em resistência ao consumo. De certa forma, seria possível compreender essa escolha como relacionada aos boicotes trazidos por Gould, Houston e Mundt (1997), dado que as práticas de distribuição estão relacionadas a uma lógica própria de uma empresa. Entretanto, por não estar ligada a nenhuma marca específica, pode-se compreender, aí, um novo hábito de consumo mapeado nesse contexto.

A este ponto, analisando os relatos dos entrevistados acerca de seus hábitos de consumo, faz-se necessário voltar à colocação de Craig-Lees (2006), que afirma haver necessidade de se identificar até que ponto estamos falando de anticonsumo/resistência ao consumo ou apenas de uma negação a certas formas de consumo, mas não a todas. Segundo a autora, seria necessário olharmos os fenômenos através de uma percepção de consumos alternativos e, nessa perspectiva, identificar quais seriam comportamentos de consumo aceitáveis ou não. Parece, portanto, que esse é um ponto crucial a ser tratado. Poucos itens ou 
categorias de consumo foram relatados pelos entrevistados como realmente negados, extirpados de suas vidas (como no caso de carne vermelha, produtos de marcas específicas, alguns produtos de higiene e limpeza e alimentos de redes de fast food). Na maioria dos casos, pode-se observar uma migração do consumo, que sai de itens que podem causar danos (seja à saúde do consumidor, seja a trabalhadores ou produtores) e vai para bens que não tragam consigo esses efeitos colaterais indesejados. Aqui, chega-se a uma conclusão similar à de outros autores (KOZINETS, HANDELMAN e LEE, 2010; ARNOULD, 2007; ZAVESTOSKI, 2002a): não há como sair completamente do contexto de consumo, pois contatos com o mercado sempre serão necessários, em maior ou menor grau.

Faz-se necessário dizer que, de acordo com o observado no campo, é possível reduzir a variedade e a quantidade de bens consumidos. Entretanto, esse processo possivelmente ocorrerá acompanhado de outro processo, que é a mudança no tipo de bens consumidos. Assim, é importante que os estudos sobre resistência ao consumo estejam preparados para lidar com essa série de hábitos de consumo que podem vir a emergir no campo: negação do consumo de alguns itens, redução do consumo de outros e troca da aquisição de certos itens por bens similares.

Em paralelo, é válido ressaltar que a compreensão dos comportamentos de resistência ao consumo ou da sua valorização são muito valiosas para a sociedade. Nesse sentido, ao identificar hábitos e objetos de resistência ao consumo, podemos contribuir para o desenvolvimento de práticas de mercado que permitam que esse grupo de indivíduos possa consumir de forma facilitada, mas reduzida, ainda.

Dada a necessidade dos entrevistados em construir redes de relacionamento que permitam um contato mais constante entre indivíduos resistentes ao consumo, pode ser interessante para uma organização atuar no sentido de criar um ambiente propício para a interação e troca de informações e bens entre essas pessoas, facilitando, assim, o estreitamento dos laços entre aqueles que compartilham ideais de consumo semelhantes.

Finalizando o trabalho e lançando uma reflexão sobre suas fragilidades, torna-se válido destacar a imaturidade do próprio tema de pesquisa. A área de estudos de resistência ao consumo (ou anticonsumo, para alguns) ainda é bastante nova e composta principalmente por trabalhos de natureza exploratória. A partir da revisão de literatura realizada, constatou-se que, ainda em 2011, buscou-se definir, afinal de contas, o que seria resistência ao consumo e o que seria anticonsumo (GALVAGNO, 2011). Assim, o tema abordado, como um todo, ainda se encontra em um momento de delimitação de territórios de pesquisa e dos fenômenos que busca estudar.

Outra limitação que pode ser destacada neste estudo é o fato de ele ter sido realizado por meio de uma seleção de sujeitos que mesclou conveniência e bola de neve. Dessa forma, alguns resultados podem ter se assemelhado excessivamente, excluindo outras formas divergentes de comportamento - principalmente no que diz respeito a motivações e práticas de resistência ao consumo desenvolvidas. Por estarmos falando sobre algumas pessoas que se conhecem e convivem nos mesmos espaços coletivos, muitas das concepções aqui retratadas podem ter sido congruentes justamente por isso. Assim, trabalhos que não utilizem uma amostragem bola de neve, mas outras técnicas, podem contribuir para uma melhor compreensão acerca da diversidade de hábitos de resistência ao consumo que podem existir.

Um maior convívio com os entrevistados, por sua vez, poderia ter contribuído para um melhor detalhamento dos objetos e práticas de resistência ao consumo adotados pelo grupo, aprimorando as descrições trazidas do campo. Contudo, deve-se considerar, aqui, o restrito tempo para a realização do trabalho de campo.

Focando no que diz respeito às práticas de resistência ao consumo, torna-se interessante a realização de estudos com abordagem longitudinal, que busquem compreender como a evolução dos comportamentos e atos relacionados se dá. Dada a insatisfação de grande parte dos entrevistados com seus hábitos de consumo atuais, seria relevante constatar se há um aprimoramento nas formas de aquisição desenvolvidas por eles com o passar dos anos. Outra motivação para um estudo longitudinal reside no fato de que a maioria dos 
entrevistados deste estudo são jovens adultos, não tendo sequer 30 anos. Afinal de contas, seriam estáveis os comportamentos de resistência ao consumo?

\section{Referências}

ARNOULD, E. J. Should consumer citizens escape the market? The Annals of the American Academy of Political and Social Science, v. 611, n. 1, p. 96-111, May 2007.

BARDIN, L. Análise de conteúdo. Lisboa: Edições 70, 1977.

BLACK, I. R.; CHERRIER, H. Anti-consumption as part of living a sustainable lifestyle: daily practices, contextual motivations and subjective values. Journal of Consumer Behaviour, v. 9, n. 6, p. 437-453, Nov./Dec. 2010.

BOVE, L.; NAGPAL, A.; DORSETT, A. Exploring the determinants of the frugal shopper. Journal of Retailing and Consumer Services, v. 16, n. 4, p. 291-297, July 2009.

BRAUNSBERGER, K.; BUCKLER, B. What motivates consumers to participate in boycotts: lessons from the ongoing Canadian seafood boycott. Journal of Business Research, v. 64, n. 1, p. 96-102, Jan. 2011.

CARU, A.; COVA, B. Revisiting consumption experience: a more humble but complete view of the concept. Marketing Theory, v. 3, n. 2, p. 267-286, June 2003.

CHERRIER, H. Ethical consumption practices: Co-production of self-expression and social recognition. Journal of Consumer Behaviour, v. 6, p. 321-335, Sep-Oct. 2007.

Anti-consumption discourses and consumer-resistant identities. Journal of Business Research, v. 62, n. 2, p. 181-190, Feb. 2009.

Custodian behavior: a material expression of anti-consumerism. Consumption Markets \& Culture, v. 13, n. 3, p. 259-272, Sep. 2010.

CLOSE, A. G.; ZINKHAN, G. M. Market-resistance and Valentine's Day events. Journal of Business Research, v. 62, n. 2, p. 200-207, Feb. 2009.

CRAIG-LEES, M.; HILL, C. Understanding voluntary simplifiers. Psychology \& Marketing, v. 19, n. 2, p. 187-210, Feb. 2002.

Anti-consumption: concept clarification and changing consumption behaviour. In: PROCEEDINGS OF THE INTERNATIONAL CENTRE FOR ANTI-CONSUMPTION RESEARCH (ICAR) SYMPOSIUM, 2006, Auckland. Annals... Disponível em: <http://docs.business.auckland.ac.nz/Doc/Anti-consumption-Concept-clarification-andchanging-consumption-behaviour-Margaret-Craig-Lees.pdf>. Acesso em: 10 jul. 2012.

DOBSCHA, S. The lived experience of consumer rebellion against marketing. Advances in Consumer Research, v. 25, n. 1, p. 91-97, Jan. 1998.

ETZIONI, A. Voluntary simplicity: characterization, select psychological implications, and societal consequences. Journal of Economic Psychology, v. 19, n. 5, p. 619-643, Oct. 1998.

FELDMAN, L. P. Societal adaptation: a new challenge for marketing. Journal of Marketing, v. 35, n. 3, p. 54-60, July 1971.

FOURNIER, S. Consumer resistance: societal motivations, consumer manifestations, and implications. Advances in Consumer Research, v. 25, n. 1, p. 88-90, Jan. 1998. 
GALVAGNO, M. The intellectual structure of the anti-consumption and consumer resistance field. European Journal of Marketing, v. 45, n. 11/12, p. 1688-1701, Nov. 2011.

GILG, A.; BARR, S.; FORD, N. Green consumption or sustainable lifestyles? Identifying the sustainable consumer. Futures, v. 37, n. 6, p. 481-504, Aug. 2005.

GOULD, S. J.; HOUSTON, F. S.; MUNDT, J. Failing to try to consume: a reversal of the usual consumer research perspective. Advances in Consumer Research, v. 24, n. 1, p. 211-216, Jan. 1997.

HEISKANEN, E.; PANTZAR, M. Toward sustainable consumption: two new perspectives. Journal of Consumer Policy, v. 20, n. 4, p. 409-442, Jan. 1997.

HOFFMANN, S.; MÜLLER, S. Consumer boycotts due to factory relocation. Journal of Business Research, v. 62 , n. 2, p. 239-247, Feb. 2009.

HUANG, M.; RUST, R. Sustainability and consumption. Journal of the Academy of Marketing Science, v. 39, n. 1, p. 40-54, Feb. 2011

IYER, R.; MUNCY, J. A. Purpose and object of anti-consumption. Journal of Business Research, v. 62, n. 2, p. 160168, Feb. 2009.

JACKSON, T. Live better by consuming less? Is there a "double dividend" in sustainable consumption? Journal of Industrial Ecology, v. 9, n. 1/2, p. 19-36, Jan. 2005.

KLEIN, N. Sem logo: a tirania das marcas em um planeta vendido. 4. ed. Rio de Janeiro: Record, 2002.

KOZINETS, R. V. Can consumers escape the market? Emancipatory illuminations from burning man. Journal of Consumer Research, v. 29, n. 1, p. 20-38, June 2002.

. ; HANDELMAN, J. M.; LEE, M. S. W. Editorial: don't read this; or, who cares what the hell anti-consumption is, anyway? Consumption Markets \& Culture, v. 13, n. 3, p. 225-233, Sep. 2010.

LASTOVICKA, J. L. et al. Lifestyle of the tight and frugal: theory and measurement. Journal of Consumer Research, v. 26, n. 1, p. 85-98, June 1999.

LEE, M. S. W.; FERNANDEZ, K. V.; HYMAN, M. R. Anti-consumption: an overview and research agenda. Journal of Business Research, v. 62, n. 2, p. 145-147, Feb. 2009.

et al. Anti-consumption and consumer resistance: concepts, concerns, conflicts and convergence. European Journal of Marketing, v. 45, n. 11/12, Editorial, Nov. 2011.

LIPOVETSKY, G. O império do efêmero: a moda e seu destino nas sociedades modernas. 2. ed. São Paulo: Companhia das Letras, 1989.

OZANNE, L. K.; BALLANTINE, P. W. Sharing as a form of anti-consumption? An examination of toy library users. Journal of Consumer Behavior, v. 9, n. 6, p. 485-498, Nov./Dec. 2010.

PEÑAlOZA, L.; PRICE, L. Consumer resistance: a conceptual overview. Advances in Consumer Research, v. 20 , n. 1, p. 123-128, Jan. 1993.

PORTILHO, F. Consumo sustentável: limites e possibilidades de ambientalização e politização das práticas de consumo. Cad. EBAPE.BR, v.3, n.3, p.1-12, 2005.

PRESS, M.; ARNOULD, E. J. Constraints on sustainable energy consumption: market system and public policy challenges and opportunities. Journal of Public Policy \& Marketing, v. 28, n. 1, p. 102-113, 2009. 
ROSSI, C. et al. Um estudo experimental de conceito de extensão de self. In: ENCONTRO DE MARKETING DA ASSOCIAÇÃO NACIONAL DE PÓS-GRADUAÇÃO E PESQUISA EM ADMINISTRAÇÃO, 2., 2006, Rio de Janeiro. Anais... Rio de Janeiro: Anpad, 2006. Disponível em: <www.anpad.org.br/ema/2006/dwn/ema2006-mktb237.pdf >. Acesso em: 10 ago. 2012.

ROUX, D. Consumer resistance: proposal for an integrative framework. Recherche et Applications en Marketing, v. 22, n. 4, p. 59-79, Dec. 2007.

RUMBO, J. D. Consumer resistance in a world of advertising clutter: the case of Adbusters. Psychology \& Marketing, v. 19, n. 2, p. 127-148, Feb. 2002.

SCHUMACHER, E. F. Small is beautiful: a study of economics as if people mattered. 2. ed. London: Sphere Books, 1974.

SHAW, D.; NEWHOLM, T. Voluntary simplicity and the ethics of consumption. Journal of Psychology \& Marketing, v. 19, n. 2, p. 167-85, Feb. 2002.

STAMMERJOHAN, C.; WEBSTER, C. Trait and situational antecedents to non-consumption. Advances in Consumer Research, v. 29, n. 1, p. 126-132, Jan. 2002.

SUAREZ, M. ; CHAUVEL, M. A. ; CASOTTI, L. Motivações e significados do abandono de categoria: aprendizado a partir da investigação com ex-fumantes e ex-proprietários de automóveis. Cad. EBAPE.BR, v. 10, n. 2, p. 411-434, June 2012.

VARMAN, R.; BELK, R. W. Nationalism and ideology in an anticonsumption movement. Journal of Consumer Research, v. 36, n. 4, p. 686-700, Dec. 2009.

XIE, C.; BAGOZZI, R.; TROYE, S. Trying to prosume: toward a theory of consumers as co-creators of value. Journal of the Academy of Marketing Science, v. 36, n. 1, p. 109-122, Mar. 2008.

ZAVEStOSKI, S. Guest editorial: anticonsumption attitudes. Psychology \& Marketing, v. 19, n. 2, p. 121-126, Feb. 2002a.

The social-psychological bases of anticonsumption attitudes. Psychology \& Marketing, v. 19, n. 2, p. 149165, Feb. 2002b. 